\title{
Modeling and Simulation of Textile Supply Chain through Colored Petri Nets
}

\author{
Francisca Santana-Robles ${ }^{1}$, Joselito Medina-Marín ${ }^{2}$, Oscar Montaño-Arango ${ }^{2}$, \\ Juan Carlos Seck-Tuoh-Mora ${ }^{2}$ \\ ${ }^{1}$ Academic Area of Engineering, School Higher of Sahagún City, Autonomous University of Hidalgo State, Pachuca, México \\ ${ }^{2}$ Advanced Research Center in Industrial Engineering, Autonomous University of Hidalgo State, Pachuca, México \\ Email: fran-santana7@hotmail.com
}

Received August 31, 2012; revised October 3, 2012; accepted October 12, 2012

\begin{abstract}
The purpose of this paper is to describe the business process modeling and simulation of a textile supply chain using Colored Petri nets. Our model takes into account both the source process and delivery logistics that exist between any two members of supply chain; moreover, we model other activities performed by the company such as manufacturing clothing. The model has been built to acquire a better understanding about the behavior of a textile company in the fulfillment of requests from costumers. The model has been built using CPN Tools. This model was built with modules for activities of the supply chain textile, e.g. receiving orders of customers, determination of production plan, procurement raw material, transportation of raw material, production and delivering products to customers. This modularized model offers some advantages to represent complex supply chains according to their structure and requirements. Thus, we can add modules easily depending on the necessary activities.
\end{abstract}

Keywords: Supply Chain; Business Process; Business Process Modeling Techniques; Colored Petri Nets

\section{Introduction}

The global competitive business environment and advances in information technology have forced enterprises to look for efficiencies in their internal operations as well as in coordinated operations with their suppliers and customers. This forced enterprises to evaluate the performance of their supply chain. Companies are improving their performance by a constant evaluation of the value added in all parts of their processes. In this field, simulation is a valuable tool to evaluate the design and redesign of business process. Simulation approach offers several advantages. Simulation is recognized to allow more realistic observation of the supply chain behavior or of complex economic models in general. It allows an analysis of the supply chain dynamics and leads to an observations along time. There are software tools to simulate business process [1-3]. In [1] the authors describe three categories of software tools that can be used for business processes simulation (BPS). These categories are business process modeling tools, business process management tools, and general purpose simulation tools. For each type they describe two specific tools and they evaluate their applicability for BPS. They categorize Protos and ARIS as Business process modeling tools; FLOWer and FileNet as business process management tools; and Arena and CPN Tools as general purpose simulation tools; this is shown in Tables 1-3. On the other hand, there are diverse techniques to model business processes in supply chain [2,3] they propose taxonomy of classification oriented to supply chain. The taxonomy includes the following process perspectives: functional, behavioral, organizational, and informational; similarly, they propose business process modeling techniques, for example Petri Nets to model functional and behavioral perspectives.

Textile and clothing industry is highly diverse and heterogeneous. Moreover, in today's markets competition is no longer on a company versus company model, but instead of supply chain versus supply chain. In order to success, companies need to achieve integration with customers and suppliers. In addition, supply chain in textile industry is complex. Supply chain is relatively long, with a number of parties involved. Consequently, careful management of supply chain is required in order to reduce lead times and reach quick response, highlighting the need to use an approach such as agility [4]. In this field, Colored Petri Nets are a valuable tool to build a model of textile supply chain because they give the flexibility in the specification of the supply chain configuration. An advantage of analyzing textile supply chain simulation by using Colored Petri Nets is that 
Table 1. Modeling capabilities.

\begin{tabular}{|c|c|c|c|c|c|c|}
\hline Feature & Protos & ARIS & FLOWer & FileNet & Arena & CPN Tools \\
\hline Ease of model building & ++ & + & + & + & + & -- \\
\hline Formal semantics/verif. & + & - & -- & -- & $+1-$ & ++ \\
\hline Workflow patterns & + & - & + & $+/-$ & + & + \\
\hline Resources and data & + & ++ & ++ & $+/-$ & + & $+/-$ \\
\hline Level of detail & ++ & ++ & ++ & + & ++ & -- \\
\hline
\end{tabular}

Table 2. Simulation capabilities.

\begin{tabular}{|c|c|c|c|c|c|c|}
\hline Feature & Protos & ARIS & FLOWer & FileNet & Arena & CPN Tools \\
\hline Performance dimensions & -- & ++ & -- & + & ++ & ++ \\
\hline Distributions & + & + & -- & -- & ++ & ++ \\
\hline Animation & -- & + & -- & + & ++ & + \\
\hline Scenarios & -- & - & -- & $+/-$ & + & + \\
\hline
\end{tabular}

Table 3. Output analysis capabilities.

\begin{tabular}{|c|c|c|c|c|c|c|}
\hline Feature & Protos & ARIS & FLOWer & FileNet & Arena & CPN Tools \\
\hline Statistics & - & -- & -- & - & ++ & ++ \\
\hline What-if analysis & -- & + & -- & -- & - & - \\
\hline Conclusion-making support & -- & + & -- & - & + & -- \\
\hline
\end{tabular}

fewer assumptions need to be made regarding the behavior of the system being modeled. The step in simulation analysis covers both output-data and experimental design. Simulation software, e.g. CPN Tools, provides basic support for running and analyzing terminated simulations and has capabilities for providing 95\% confidence intervals. An advantage of Coloured Petri Nets is that there exist the potential for varying the values of non-numerical parameters when defining different configurations.

We have reviewed the literature and we have found that Coloured Petri Nets have been used to model different types of supply chains. However, they have not been used to model and simulate textile supply chain. The innovation of this paper is to show a model built with modular Coloured Petri Nets. This model was built with modules for activities of the supply chain textile, e.g. receiving orders of customers, determination of production plan, procurement raw material, transportation of raw material, production and delivering products to customers. This modularized model offers some advantages to represent complex supply chains according to their structure and requirements. Thus, we can add modules easily depending on the necessary activities.

This paper shows the business process modeling and simulation of a textile supply chain using Colored Petri nets. The objective of the model has been built to acquire a better understanding about the behavior of the textile company in the fulfillment of requests from costumers. The model has been built using CPN Tools.

\section{Supply Chain}

"One of the most significant paradigms shift of modern business management is that individual business no longer compete as solely autonomous entities, but rather as supply chain". Success of the single business will depend on management's ability to integrate the company's intricate network of business relationships [5].

A supply chain is composed of all parties involved directly and indirectly in the fulfillment of request from a costumer [6]. Figure 1 shows a supply chain network formed out of complex intercommunications amongst various manufacturing companies and service providers such as raw material vendors, original equipment manufacturers, logistics operators, warehouses, distributors, retailers and customers [7]. There are four characteristics of a supply chain: first, it goes through several stages of increasing intra- and inter-organizational, vertical coordination. Second, it includes many independent firms, 


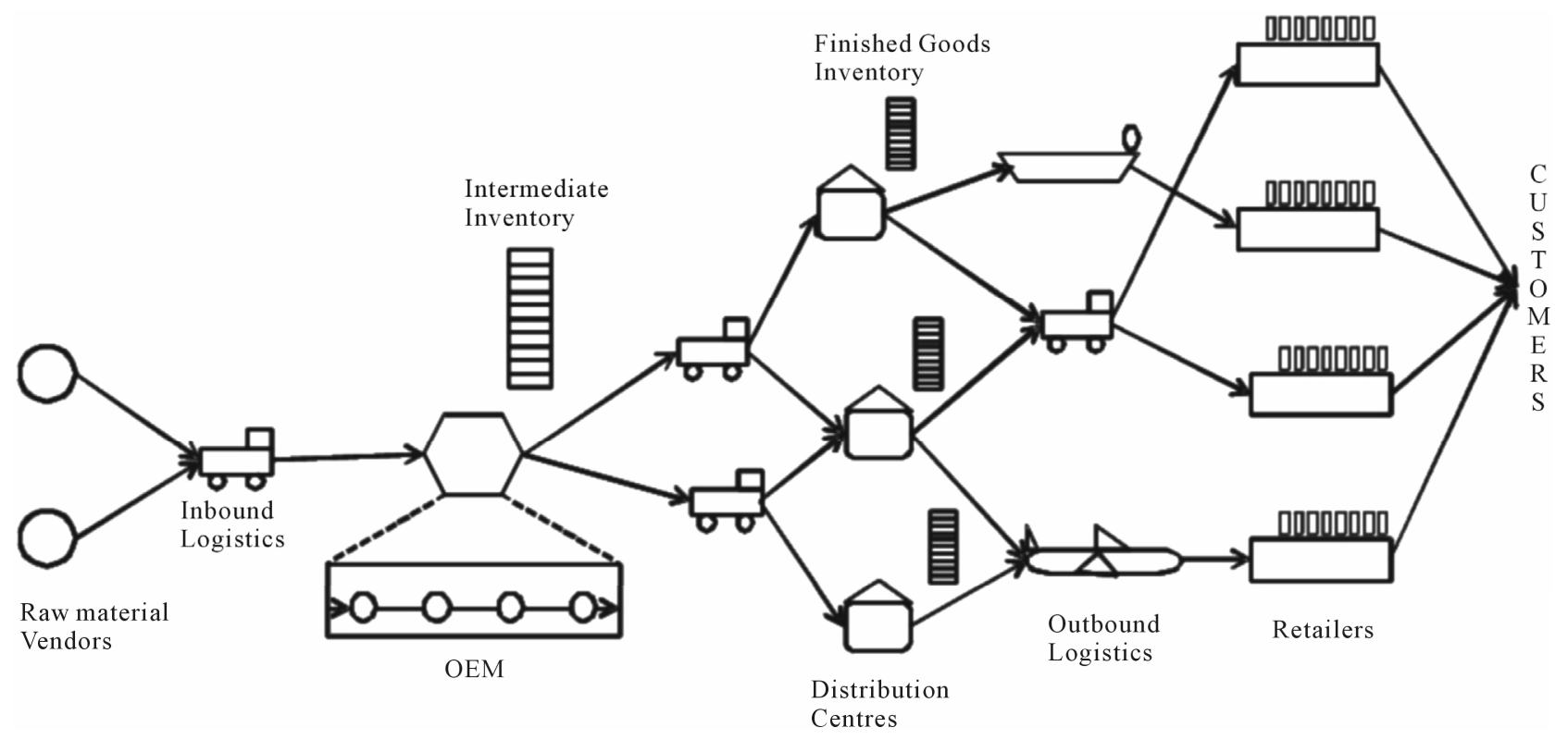

Figure 1. The supply chain network.

suggesting that managerial relationship is essential. Third, a supply chain includes a bi-directional flow of products and information, and managerial and operational activities. Fourth, chain members aim to fulfill the goals to provide high customer value with an optimal use of recourses.

In addition, the management of multiple relationships across the supply chain is referred to as Supply Chain Management (SCM). SCM deals with total business process excellence and represents a new way of managing the business and relationships with others members of the supply chain. SCM is the integration of key business processes from end user through original suppliers that provides products, services, and information that add value for customers and others stakeholders [5].

\section{Textile Garment Supply Chain}

The Textile garment supply chain is comprised of a group (garment supply chain) and members (retailer, apparel, maker, textile manufacturer and fibre manufacturer). The network is arranged in the order that the flow of materials, processes, and information occurs between its members [8-11]. Figure 2 depicts a design of the textile garment supply chain. Customer demand is relayed by retailer to apparel maker, textile manufacturer, fibre manufacturer and ultimately to cotton grower.

\section{Colored Petri Nets}

Colored Petri Nets (CPN) is a graphical oriented language for design, specification, simulation and verification of systems. The more compact representation has been achieved by equipping each token with an attached data value (called the token color). The data value may be of arbitrarily complex type. The use of color sets in $\mathrm{CPN}$ is totally analogous to the use of types in programming languages. Typical examples of application areas are communication protocols, distributed systems, imbedded system, automated productions systems, and workflow analysis [12-14]. On the other hand, CPN Tools is a tool used to construct, modify, syntax check and simulate CPN. The most important advantage of using computerized CPN Tools is the possibility of obtaining better result. The CPN editor provides the user with a precision and quality which by far exceed the normal manual drawing capabilities of human beings. A second advantage is the possibility of obtaining faster results. As an example, the CPN editor multiplies the speed by which modifications can be made. A third advantage is the possibility of making interactive presentations of the analysis results. The CPN simulator makes it easy to trace the different occurrence sequences in a CPN [12].

\section{Model of the Textile Supply Chain}

Figure 3 depicts the supply chain of the textile company modeled in this paper. Supply chain is linked by five members: 1) Fibrer manufacturers (wool and synthetic fibres), 2) Textile and accessories manufacturers, 3) Apparel maker, 4) Distribution center, and 5) Retailers. This company is apparel marker. It has two types of suppliers (Textile manufacturer and Accessories Manufacturer) and three customers (two retailers and one distribution centre); moreover, it has supplier's suppliers (fibre manufacturer) and customer's customer (two retailers).

In addition, the garment production processing steps 


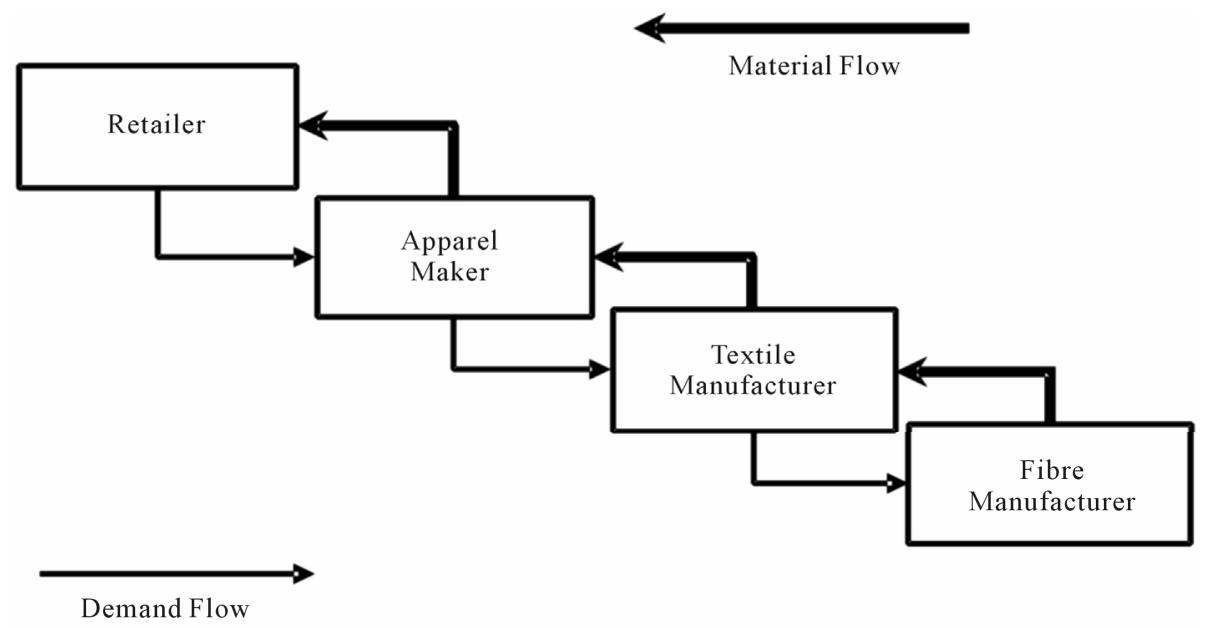

Figure 2. Textile garment supply chain.

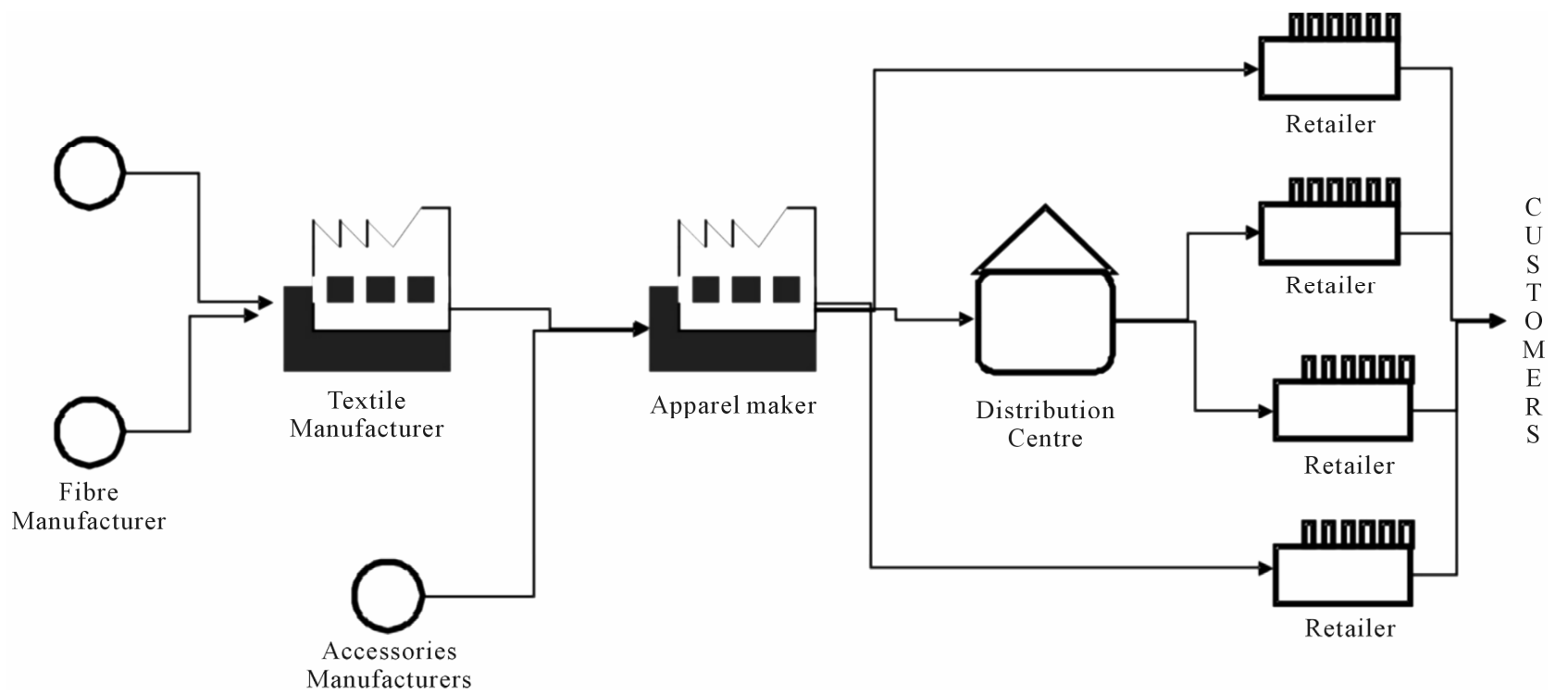

Figure 3. The supply chain of the textile company modeled.

and techniques involved in the manufacturing garments for the large scale of production in industrial basis for business purposes is called Garments Manufacturing Technology. The basic Production Flowchart of a garment includes following activities (some of the process can be added or removed): Design or Sketch, Pattern Design, Sample Making, Production Pattern, Grading, Marker Making, Spreading, Cutting, Shorting and Bundling, Sewing and Assembling, Inspection, Pressing or Finishing and Packing. In this case study, we focus on the following activities: Design, Cutting, Sewing and Assembling, Finishing and Packing.

\subsection{Problem Description}

The company has high inventory levels due to uncertainty and risks throughout the chain and also high pro- duction costs due to low fulfillment rate of suppliers. In addition, the company has low fulfillment rate.

\subsection{Model Description}

Figure 4 shows the conceptual model of the business process of the company. This process is modeled through of modular Colored Petri Nets. Because the Petri nets has been proven an effective language for modeling concurrent and asynchronous systems because of its clear graphical representation and extensive expressiveness for modeling both qualitative and quantitative systems. Fostered by its highly human, comprehensible and visual format, it is also used for modeling structural dynamic systems in production. A modular colored Petri net (MCPN) is a modular structure which is composed of one or more colored Petri net modules. Each colored 


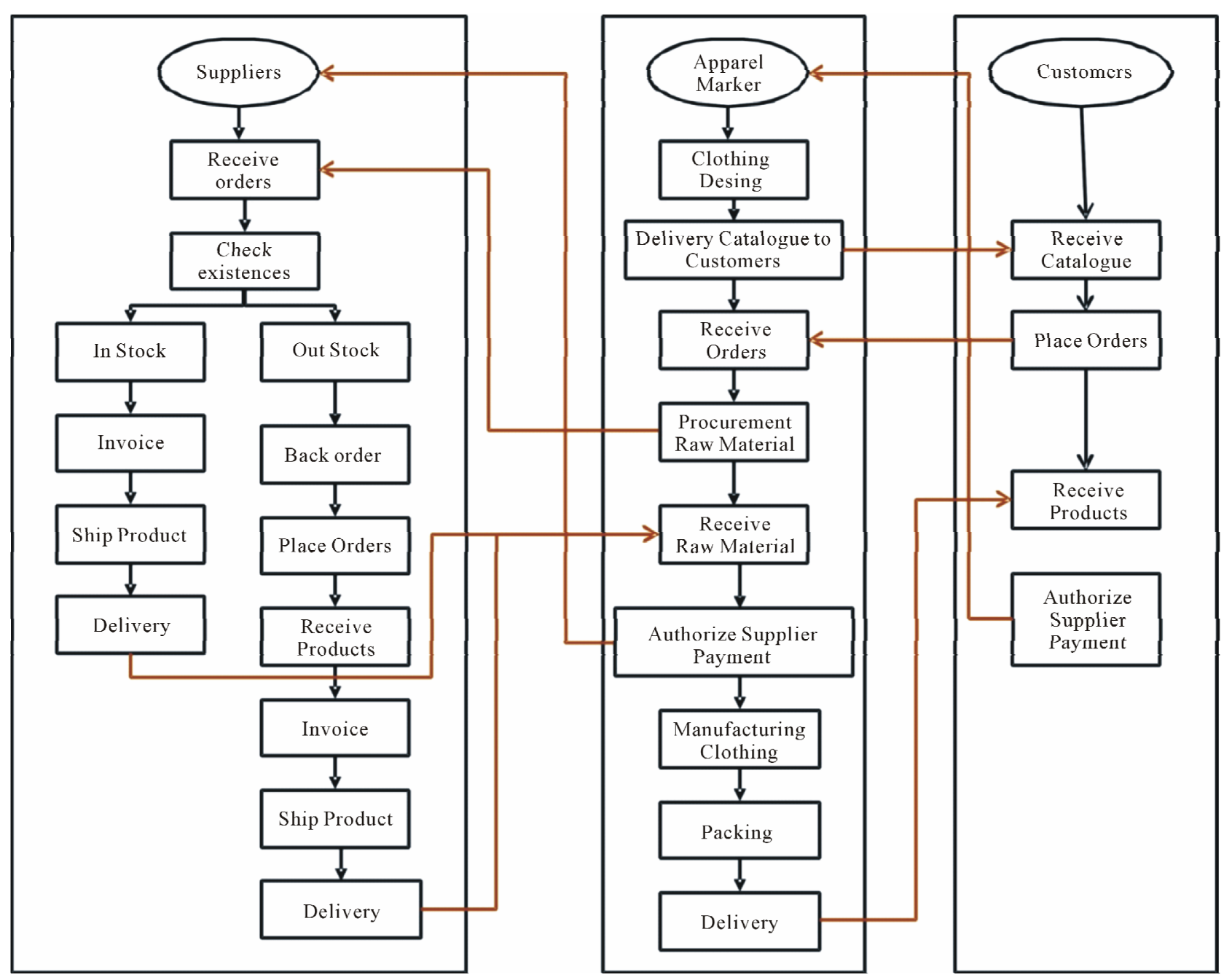

Figure 4. Conceptual model of supply chain of the textile company (Source processes, manufacturing and delivery logistics).

Petri net module, in turn, encapsulates a CPN. Our model begins with the design of clothing; next the catalogues are made and are delivered to customers. Customers place orders, company receives these orders and determines the quantity to order, next company places orders to suppliers. Suppliers receive orders and check existences in their inventory, if they have enough raw materials in stock then schedule products deliveries, generate the corresponding invoice and deliver products; however, if suppliers are out stock then they place orders to suppliers, receive products, authorize suppliers' payment and schedule products deliveries, invoice and deliver products. Company receives products, authorizes suppliers' payment and begins manufacturing clothing, packing and delivering to customers. The process described above is shown in Figure 4. In addition, these processes shown in Figures 4-9 are modeled in CPN Tools. Figure 5 shows the design process, the delivering of the catalogues to customers, receiving of orders and compute of raw materials; similarly, Figure 6 shows the place orders to suppliers, the receiving to orders suppliers', checking existences and confirmation of the orders. Figure 7 shows the compute of the transportation cost from corporation suppliers to company and date of delivering. Figure 8 shows garment manufacturing process (Design, Cutting, Sewing and Assembling, Finishing and Packing) and deliver products to customers. Finally, Figure 9 shows some results obtained after run the model. It is important to note that this textile supply chain is type pull because trough the customers the supply chain activities start. Furthermore, trends in clothing markets change frequently.

\section{Conclusions}

We described the modeling of the supply chain of the textile company using Colored Petri nets. CPN are a powerful tool to model complex system of manufacturing and logistics process which include: transportation, inventory management, order processing, warehousing, 


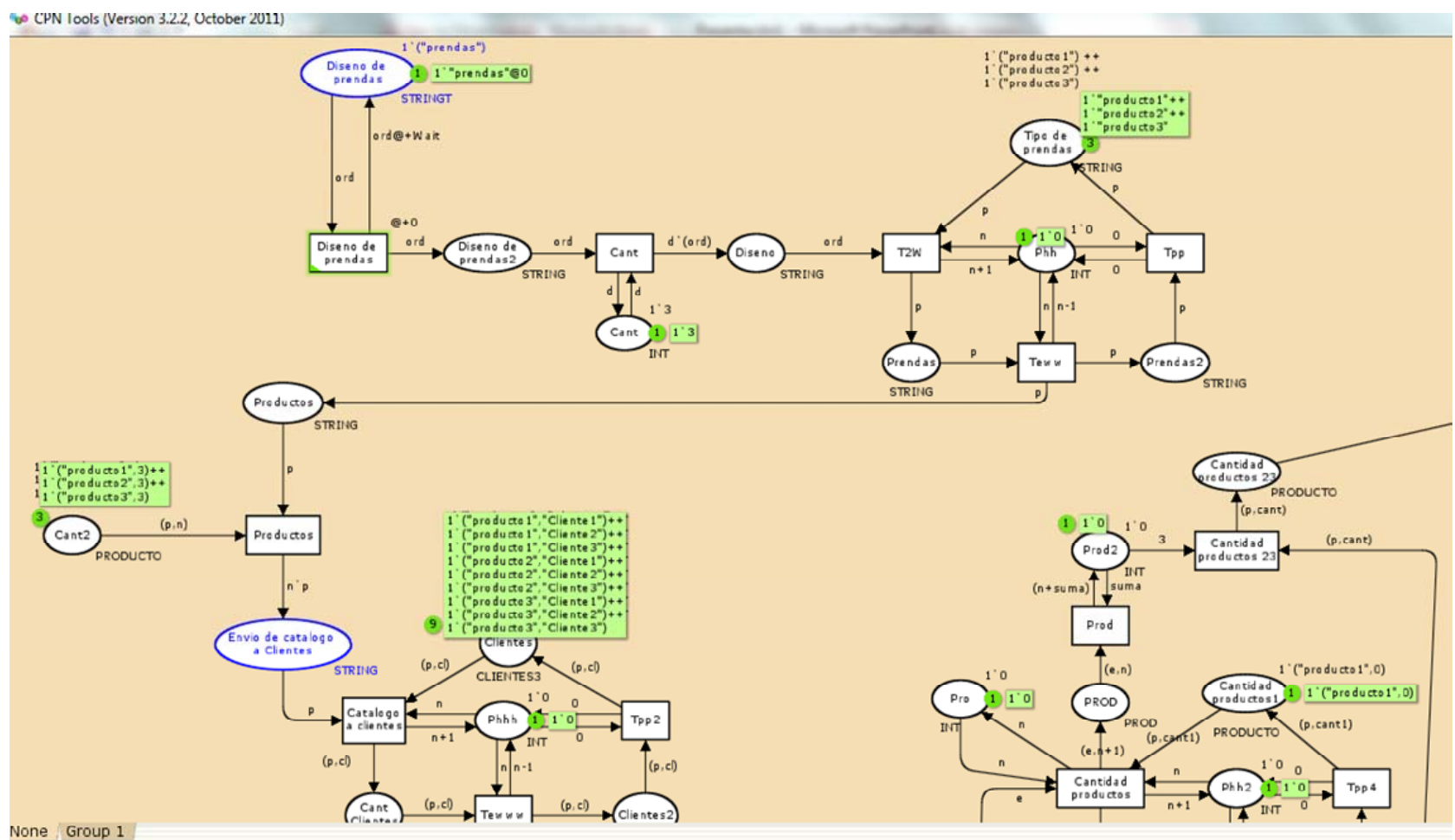

Figure 5. Design process, delivering of the catalogues to customers, receiving of orders and compute of raw materials.

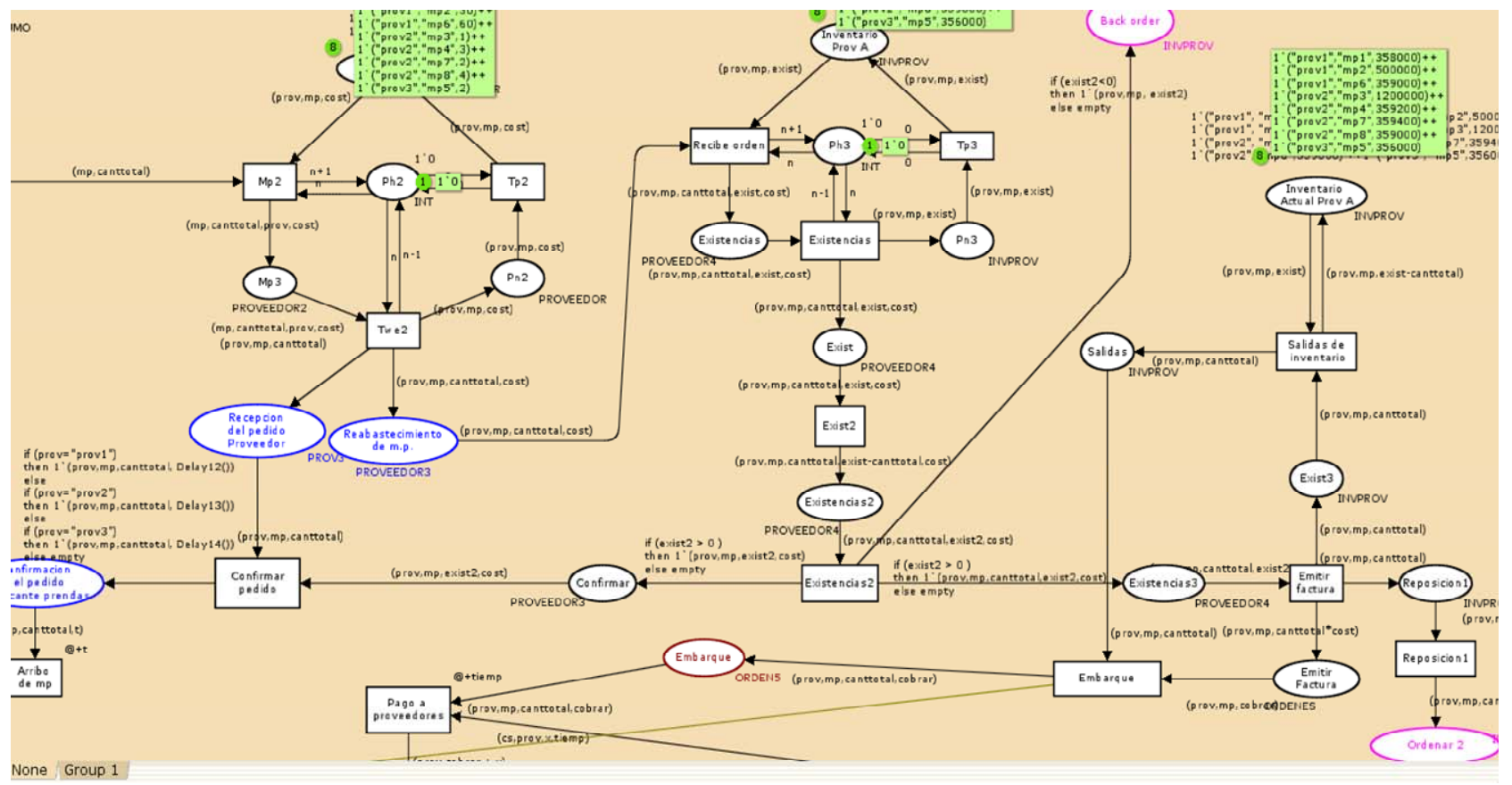

Figure 6. Place orders to suppliers, the receiving to orders suppliers', checking existences and confirmation of the orders.

distribution and production. With our model we can know the company performance. We can be able to know how affect the behavior of the supplier's company in the fulfillment of requests from costumers' company. We could observe how affect the quantity of existences in inventory in the manufacturing processes of company; moreover could know the importance of sharing information between members of supply chain to reduce uncertainty. In the results obtained after run the model we could observe the average of occupation of the production 


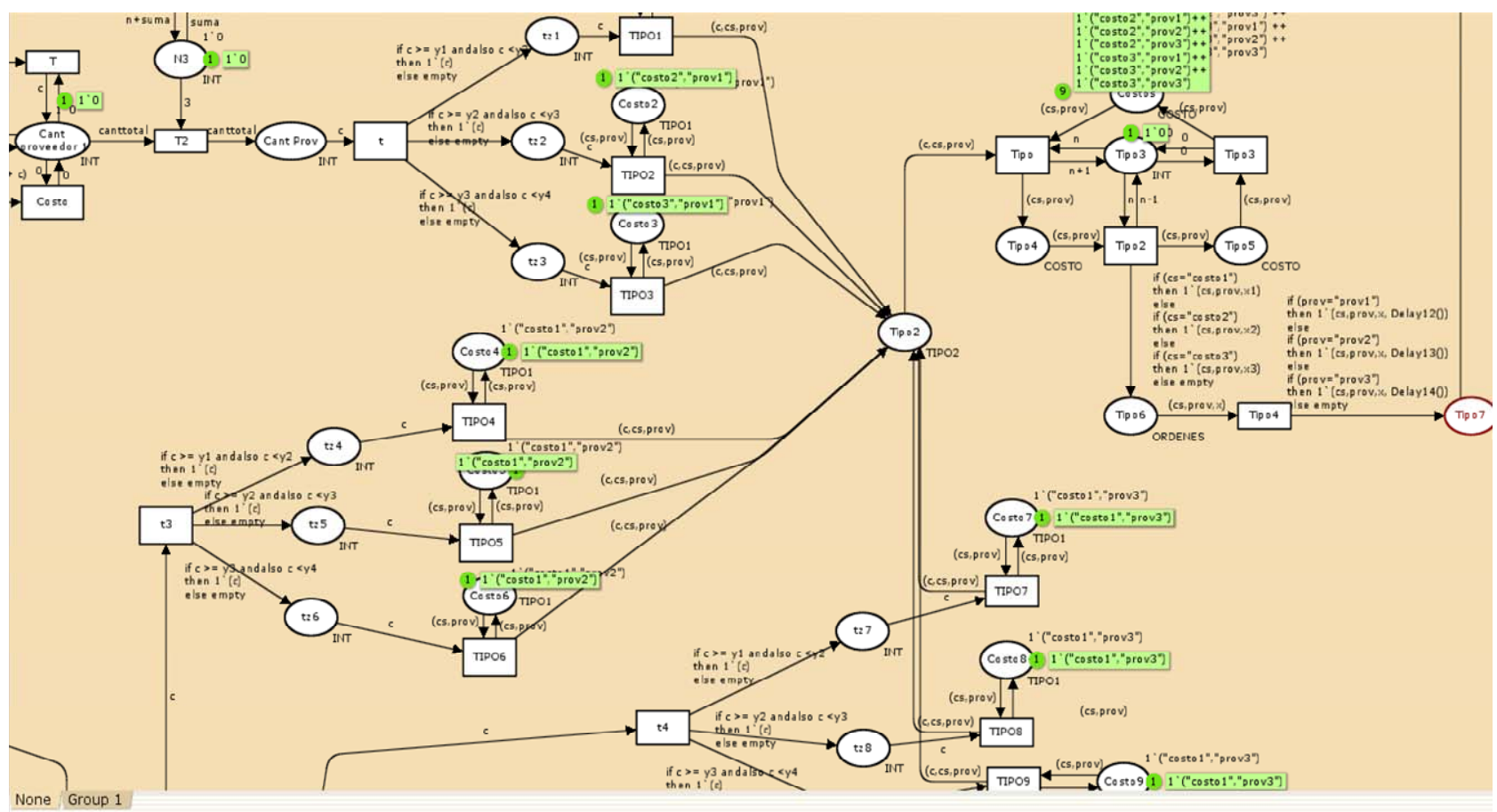

Figure 7. Compute of the transportation cost from corporation suppliers' to company and date of delivering.

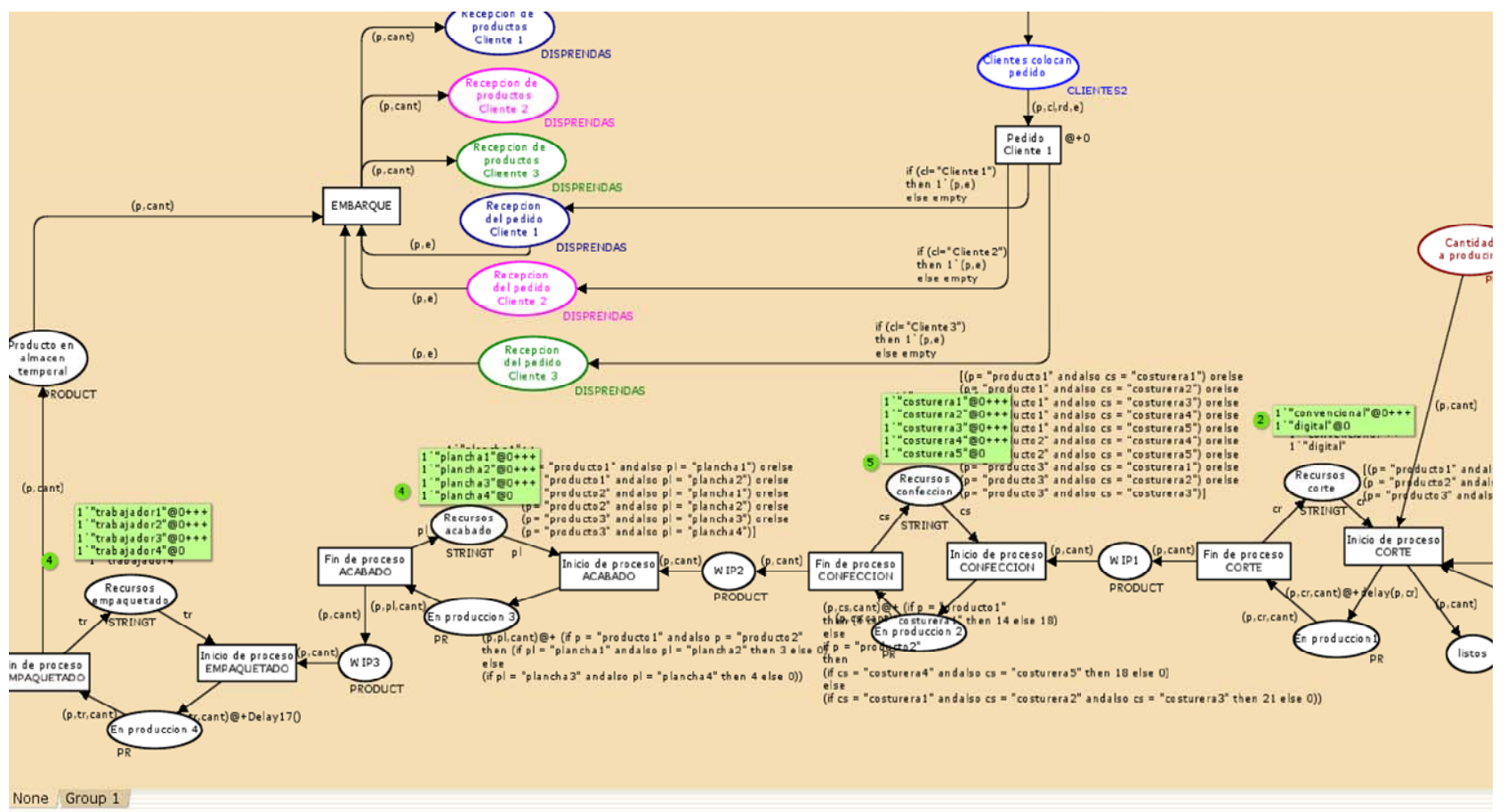

Figure 8. Garment manufacturing process and deliver products to customers.

equipment. This is important for the reason that in the textile supply chain require to eliminate waste including time because retailers require rapid replenishment of product, and shipments need to meet strict requirements in terms of the delivery times, order completeness and accuracy. In addition, is necessary the supply chain need to find an effective response to constantly changing and highly competitive business environment. With simulation results to able to react to possible volatile fluctuations in demand. 


\begin{tabular}{|l|c|c|c|c|}
\hline \multicolumn{7}{|c|}{ Timed statistics } \\
\hline Name & Count & Avrg & Min & Max \\
\hline Marking_size_New_Page'En_produccion1_1 & 26 & 0.083333 & 0 & 2 \\
\hline Marking_size_New_Page'En_produccion_2_1 & 26 & 0.088889 & 0 & 3 \\
\hline Marking_size_New_Page'En_produccion_3_1 & 26 & 0.000000 & 0 & 1 \\
\hline Marking_size_New_Page'En_produccion_4_1 & 26 & 0.019444 & 0 & 1 \\
\hline Marking_size_New_Page'Recursos_corte_1 & 26 & 1.916667 & 0 & 2 \\
\hline Marking_size_New_Page'Recursos_acabado_1 & 26 & 4.000000 & 3 & 4 \\
\hline Marking_size_New_Page'Recursos_confeccion_1 & 26 & 4.911111 & 2 & 5 \\
\hline Marking_size_New_Page'Recursos_empaquetado_1 & 26 & 3.980556 & 3 & 4 \\
\hline
\end{tabular}

Figure 9. Results obtained after run the model.

In the further research, we want to extend our model to calculate some performance attributes of the SCOR Model such as Delivery Performance, Fill Rates, Perfect Order Fulfillment and Cost of Goods.

\section{REFERENCES}

[1] M. H. Jansen-Vullers and M. Netjes, "Business Process Simulation-A Tool Survey," Workshop and Tutorial on Practical Use of Colored Petri Nets and the CPN Tools, 2006.

[2] G. M. Giaglis, "A Taxonomy of Business Process Modeling and Information Systems Modeling Techniques," The International Journal of Flexible Manufacturing Systems, Vol. 13, No. 2, 2001, pp. 209-228. doi:10.1023/A:1011139719773

[3] R. Sanchis, R. Polery and A. Ortiz, "Business Process Modelling Techniques in Supply Chain," Vol. 20, No. 2, 2009, pp. 29-40. doi:10.4067/S0718-07642009000200005

[4] M. Bruce, L. Daly and N. Towers, "Lean or Agile: A Solution for Supply Chain Management for Textile and Clothing Industry?" International Journal of Operations and Production Management, Vol. 24, No. 2, 2004, pp. 151-170. doi:10.1108/01443570410514867

[5] D. Lambert and M. Cooper, "Issues in Supply Chain Management," Industrial Marketing Management, Vol. 29 , No. 1, 2000, pp. 65-83. doi:10.1016/S0019-8501(99)00113-3

[6] S. Chopra and P. Meindl, "Supply Chain Management: Strategy, Planning and Operations," Prentice Hall, Upper Saddler River, 2004.

[7] N. Viswanadham and N. R. Srinivasa Raghavan, "Per- formance Analysis and Design of Supply Chains: A Petri Nets Approach," Journal of the Operational Research Society, Vol. 51, No. 10, 2000, pp. 1158-1169.

[8] C. Chandra and S. Kumar, "An Application of a System Analysis Methodology to Manage Logistics in a Textile Supply Chain," Supply Chain Management: An International Journal, Vol. 5, No. 5, 2000, pp. 234-244. doi:10.1108/13598540010350493

[9] J. K. C. Lam, "Textile and Apparel Supply Chain Management in Hong Kong," International Journal of Clothing Science and Technology, Vol. 18, No. 4, 2006, pp. 265-277. doi:10.1108/09556220610668491

[10] S. Gary and H. Jaramillo, "Integration the US Textile and Apparel Supply Chain with Small Companies in South America," Supply Chain Management: An International Journal, Vol. 11, No. 1, 2006, pp. 44-55. doi:10.1108/13598540610642466

[11] K. Ka-Leung, C. Ying and E. W. T. Ngai, “An Instrument for Measuring Supply Chain Flexibility for the Textile and Clothing Companies," European Journal of Operational Research, Vol. 222, No. 2, 2012, pp. 191-203. doi:10.1016/j.ejor.2012.04.027

[12] K. Jensen, "Colored Petri Nets Basic Concepts, Analysis Methods and Practical Used," Springer-Verlag, Berlin, Heidelberg, New York, 1977.

[13] K. Jensen and L. M. Kristensen, "Colored Petri Nets Modelling and Validation of Concurrent Systems," SpringerVerlag, Berlin, Heidelberg, New York, 2009. doi: $10.1007 / \mathrm{b} 95112$

[14] W. M. P. van der Aalst, "Putting High-level Petri Nets to Work in Industry," Computers in Industry, Vol. 25, No. 1, 1994, pp. 45-54. doi:10.1016/0166-3615(94)90031-0 